\title{
A MEASURE OF THE VARIABILITY OF REVENUE IN AUCTIONS: A LOOK AT THE REVENUE EQUIVALENCE THEOREM
}

\author{
FERNANDO BELTRÁN AND NATALIA SANTAMARÍA
}

Received 30 August 2005; Revised 6 June 2006; Accepted 7 June 2006

One not-so-intuitive result in auction theory is the revenue equivalence theorem, which states that as long as an auction complies with some conditions, it will on average generate the same revenue to an auctioneer as the revenue generated by any other auction that complies with them. Surprisingly, the conditions are not defined on the payment rules to the bidders but on the fact that the bidders do not bid below a reserve value-set by the auctioneer-the winner is the one with the highest bidding and there is a common equilibrium bidding function used by all bidders. In this paper, we verify such result using extensive simulation of a broad range of auctions and focus on the variability or fluctuations of the results around the average. Such fluctuations are observed and measured in two dimensions for each type of auction: as the number of auctions grows and as the number of bidders increases.

Copyright (c) 2006 F. Beltrán and N. Santamaría. This is an open access article distributed under the Creative Commons Attribution License, which permits unrestricted use, distribution, and reproduction in any medium, provided the original work is properly cited.

\section{Introduction}

In the early 1980s, a series of papers appeared in the economics literature on auctions, dealing specially with the issue of the expected revenue to an auctioneer in a singleobject buyer's auction. The pioneer work of Vickrey offered the first insights into the expected revenues of four different auctions finding them to be equivalent (Milgrom [4]). The main result, appearing in [6] by Riley and Samuelson, and Myerson [5] became known as the revenue equivalence theorem. The theorem states that as long as an auction complies with some conditions, it will on average generate the same revenue to an auctioneer as the revenue generated by any other auction with the same conditions. Surprisingly the conditions are not defined on the payment rules but on the facts that bidders do not bid below a reserve value-defined by the auctioneer-the winner is the one with the highest bid and there is a common equilibrium bidding function used by all bidders. 
More specifically, as Klemperer [3] puts it: "each of a given number of risk-neutral potential buyers of an object has a privately known signal independently drawn from a common, strictly increasing, atomless distribution. Then any auction mechanism in which

(i) the object always goes to the buyer with the highest signal, and

(ii) any bidder with the lowest-feasible signal expects zero surplus

yields the same expected revenue (and results in each bidder making the same expected payment as a function of her signal)."

The result applies both to private-value models - every player's value is independently drawn from the same continuous distribution on a finite interval—and to more general common-value models - the value of the object is the same for all players, but it is unknown at the time of the bidding-provided that bidders' signals are independent.

\section{Is an auctioneer interested in the variability of the mean revenue?}

The revenue equivalence theorem has been a remarkable piece in the construction of a theory of auctions. Under the stated conditions, such seemingly different auctions as the all-pay or the second-price sealed-bid yield the same expected revenue. As Milgrom [4] affirms, one practical use of the revenue equivalence theorem is as a benchmark for the analyses of revenues in auctions, when the assumptions of the theorem do not hold or cannot be verified properly.

A main concern to be addressed in this paper is that of an auctioneer trying to decide which auction to use. Suppose an auctioneer has an object to sell. If he knew that such an object represented a private value to all potential bidders, bidders values were independent and any bid placed for the auction was larger than a reserve value-which would happen in the case of at least one bidder informed about such price and willing to participate in the auction - then the auctioneer should be indifferent among several different auctions he could choose from. For instance, he could use a first-price sealed-bid auction or a "sad losers" auction (Riley and Samuelson [6]). The latter is an auction in which every bidder, except the winner, pays his/her bid. There could, however, be a very practical concern that the auctioneer needs to deal with: the revenue equivalence theorem states its result in terms of the expected revenue to the seller but the seller not always likes or needs to run a large number of auctions of the same object-or type of object. Maybe, what is being sold is not ordinary merchandise but a right for the exploitation of a public good. Assuming the auctioneer will award the object to the highest bidder, would the design of the auction - that is, the payment from the bidders-matter to the auctioneer? The theorem would ease the auctioneer's worries with a categorical "it would not." Well, "it would not" if the auctioneer ran a sufficient number of auctions so that on average his revenue from each auction was the one predicted by the theorem.

If the auctioneer is not running many auctions or if he is just auctioning one object, his attention may shift to find a measure of the variability of such average or mean value. For instance, in [7] by Waehrer et al., it is shown that a risk-averse auctioneer prefers a firstprice auction to a second-price auction, and in turn he prefers a second-price auction to an English auction. In this paper, we use a simulator to better understand how large around the mean are the variations of running several auctions for at least six different 
auctions, which under the assumptions of the theorem should yield the same (expected) revenue.

In this paper, firstly, we verify the results of the theorem running simulations of a broad range of auctions and, secondly, we focus on the variability or fluctuation about the average revenue of an auction with a given number of bidders, we attempt to find a criterion that helps the auctioneer to decide about the type of auction to be used. The fluctuations are observed and measured in two dimensions for each type of auction: as the number of instances of a given auction grows and as the number of bidders in the auction increases.

\section{The revenue equivalence theorem}

Theorem 3.1 (Klemperer [3]). In an auction of a single object, suppose there are $n$ riskneutral potential bidders with privately known independent signals drawn from a common distribution $F(v)$. Then any auction mechanism in which (i) the object always goes to the buyer with the highest signal, and (ii) any bidder with the lowest-feasible signal expects zero surplus yields the same expected revenue.

For the proof, see Klemperer [3, Chapter 1, page 17].

\section{Optimal bids}

In all auctions considered here, the winner is the bidder with the highest bid; ties are broken randomly. In an all-pay auction, every bidder pays his/her bid; in sad losers auction, all but the winner pay their bids; in last-pays auction, only the bidder with the lowest bid pays. In Santa Claus auction, the auctioneer takes the payment from the winner and gives back a portion of it to all bidders, including the winner (Riley and Samuelson [6]). Firstprice and second-price are the so-called traditional auctions where the amount paid by the winner is the highest bid or the second highest bid, respectively.

We have used the result above to calculate the optimal bids in several auctions which comply with the conditions of the theorem. Starting with basic results for two bidders presented in [6] by Riley and Samuelson, we previously calculated (Beltrán et al. [1]) the optimal bids for $n$ bidders in all-pay, sad losers, last-pays and Santa Claus. To the latter, we have added the first-price auction, whose optimal bid expression is found in [2] by Gibbons, and the second-price auction where it is optimal for a bidder to bid his true value (Klemperer [3]). Optimal bid functions for $n$ users in the auctions mentioned can be found in Appendix A.

\section{Simulating the auctions}

In order to perform the computational experiments, we used a random number generator to determine the bidders' valuations; the valuations are uniformly drawn from the interval $[0,1]$. Every run consists of a number of auctions or scenarios of the auction, for a predefined number of bidders; the bids are calculated according to the optimal bid functions obtained in the preceding section. The simulator determines the optimal allocation and the revenue for the seller, repeating this procedure until the number of desired scenarios is completed. The runs are conducted while varying the number of bidders and 


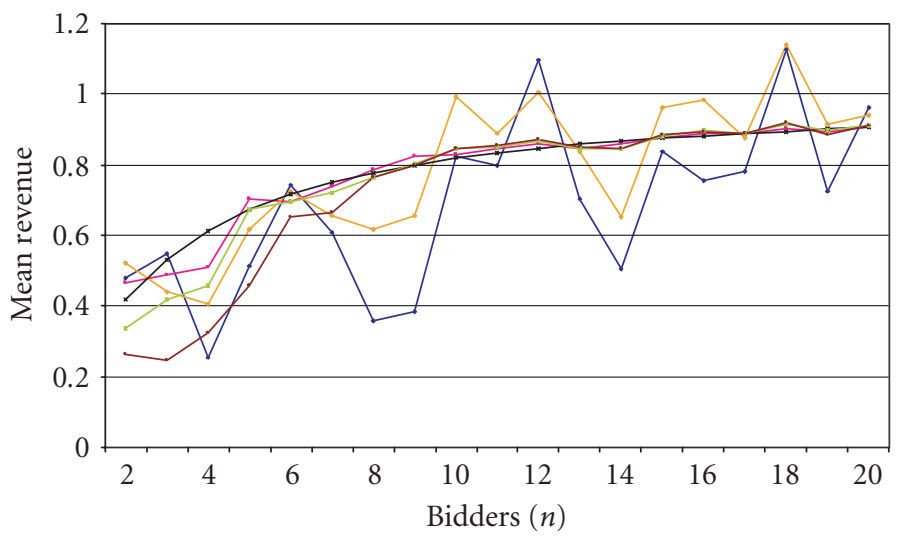

$\begin{array}{ll}\text { — Sad losers } & \text { - Expected revenue } \\ \text { - Santa Claus } & \text { - First price } \\ \text { All pay } & \quad \text { Second price }\end{array}$

Figure 5.1. Mean revenue for 5 auction types.

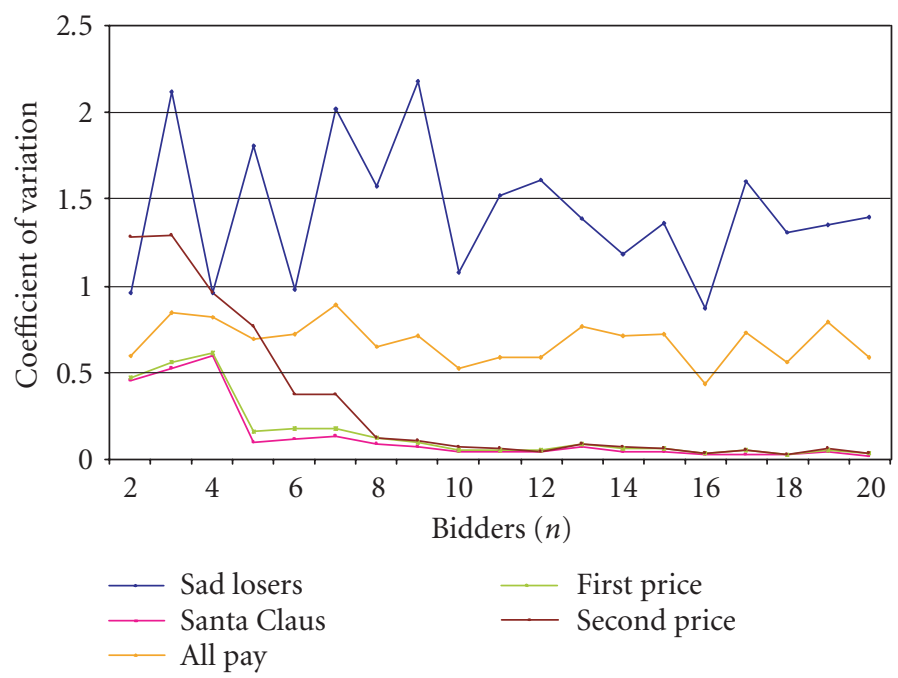

Figure 5.2. Coefficient of variation for 5 auction types.

the number of scenarios. For each run, we calculated the mean revenue for the auctioneer and the coefficient of variation of the revenue, defined as the ratio of the variance with respect to the square of the expected value. This was done for each of six auctions: first-price, second-price, all-pay, Santa Claus, sad losers, and last-pays. The analysis that follows uses data from all auctions except last-pays, which because of its particular design deserves a special analysis in a subsequent section. Figures 5.1 and 5.2 show, for up to 20 bidders, the average and coefficient of variation for 20 scenarios. 
It can be observed that as the number of bidders increases, the mean revenue approaches the theoretical expected revenue and the variation around the mean decreases for most of the auction types. However, this variation is significantly different for sad losers and all-pay. This is also confirmed if the number of scenarios is increased. Appendix $\mathrm{B}$ illustrates this fact, where simulations results are reported in which 50 and 100 scenarios were performed for auctions with up to 20 bidders.

In the traditional auction formats (first-price and second-price auctions), fluctuations around the mean revenue are less than those of the other auctions, except for the Santa Claus auction. By the central limit theorem, increasing the number of scenarios, the degree of variability around the mean revenue decreases. Runs with 100 and 500 scenarios were also done. Those results show that as a function of the number of bidders, the coefficient of variation converges to zero for first-price, second-price, and Santa Claus, and seems to settle around 0.65 for all-pay. However the variability of sad losers remains high when compared to the others and does not seem to converge to any value.

\section{A real experiment}

Our previous experimentation with auctions in a broader setting has included the development of SUBASTIN (http://subastas.uniandes.edu.co), a web application for the administration of auctions over the Internet. SUBASTIN collects the bids from the players and determines the winner in a fairly large family of auctions (SUBASTIN administers all the auctions described in this paper plus several dynamic auctions such as ascending English, descending Dutch, German, and simultaneous ascending auctions. SUBASTIN is also capable of administering single-bid combinatorial auctions). Using SUBASTIN, we ran a real all-pay auction where bidders were students of a Game Theory Class (Universidad de Los Andes, Departamento de Ingeniería Industrial, Game Theory Course, January-May 2004). When bidding to get the object being auctioned, the bidders used their SUBASTIN Web windows; the results are summarized in Table 6.1. (Bids are stated in Colombian pesos (COP). In April 2004, the exchange rate was US $\$ 1=$ COP $\$ 2700$. This illustrates that the object auctioned did not mean a high expense to any bidder.)

The market value of the auctioned object was about $\$ 15000$. So, the auctioneer was not only able to recover the cost of purchasing the object, but also able to make quite a bit of a profit. It is clear that at least three bidders were not interested at all; some others bid a very low value. It is tempting to say that each of these bidders thought of winning the auction expecting others to bid low as well. Perhaps they disliked the idea that the auctioneer could profit excessively. However, quite a few bid high, even close to the market value. This behavior contrasts the behavior of those who bid low.

This experiment is just a sample of what could happen in a nontraditional auction, even though such type is one that satisfies the assumption of the theorem, at least in regard to who wins the auction and the seeming independence of the bidders' valuations. Simulations of all-pay show a larger variability of the expected revenue than that of firstprice, second-price, and Santa Claus auctions. The results from the experiment shed some light on the possibility that an auctioneer prefers using one auction over other. 
Table 6.1. Bids in a real all-pay auction.

\begin{tabular}{lc}
\hline Bidder ID & Bid \\
\hline El Coyote & 0 \\
Ricky Ricon & 1000 \\
Carmedelgad3 & 10000 \\
Juangalind & 12000 \\
Andrevasque1 & 10000 \\
Andresantac & 500 \\
Diego Martin & 100 \\
Diegodiazm & 1000 \\
Rubenjacome & 100 \\
Javieguarin & 0 \\
Florbetanc & 100 \\
Mauriescoba & 0 \\
Ricarpedraz & 15000 \\
Paulabarrie & 20000 \\
J2zp & 13000 \\
Francovoyageur & 14000 \\
Sebassalaza & 100 \\
Maurisuarez & 2000 \\
Juanredond & 1000 \\
El Mani & 500 \\
\hline
\end{tabular}

\section{Some experimental difficulties of last-pays}

Results shown in Appendix B for simulation runs of last-pays are not quite encouraging. Expected revenue in auctions in which a few bidders are simulated is close to the theoretical value calculated in Appendix A. However, results no longer seem to hold as long as more bidders are included.

In last-pays, the auctioneer has positive revenue only if the valuation for all the bidders is greater than the auctioneer's reserve value. If at least one bidder's valuation is less than the reserve value, the revenue for the auctioneer will be zero as such a bidder is the one who should be paying. The probability that all valuations are greater than the reserve value decreases when the number of bidders increases; this also increases the probability that the auctioneer's revenue is zero. The results of the simulation runs performed on last-pays show that when the number of bidders increases, the expected revenue for the auctioneer goes to zero. Appendix B shows the difference in expected revenue obtained when a 5000 -scenario simulation is compared to a 50000-scenario simulation.

\section{Conclusions}

For each run, that is, an auction type simulated several times with a given number $n$ of users, we have found the expected revenue to the auctioneer and a measure of the variability of such result using its coefficient of variation. When the number of bidders is fixed, we have then compared such measure across several auction types. If an auctioneer 
does not have the time or the need to run a large number of auctions, would the result provided by the theorem influence his decision as to which auction to use? If he is interested in maximizing his revenue, all-pay or sad losers seem to provide some greater degree of variability of the expected revenue. From the results, we can argue that an auctioneer seeking to improve his revenue may prefer one auction to another, if he is willing to bear the risk implied in the variance of the revenue.

For the real auction we performed, if we believed that the assumptions of the theorem held, in particular, that the students' signals were independent, then we might assert that the auctioneer could have used a first-price or second-price auction instead of the allpay auction. In the context of the main result of the theorem, we would have expected the same revenue for the auctioneer without worrying about the type of auction administered. However, as the results of simulations showed, the variability of the revenue is quite different in all-pay when compared to the more traditional first-price and second price. It is in this sense that the result from the real experiment becomes relevant to the inquiry about the auctioneer's question posed at the beginning and the risk he incurs when answering such a question.

\section{Appendices}

\section{A. Bid functions (Beltrán et al. [1])}

Let $\pi$ represent the bidder expected revenue, $v$ the bidder's value, $b$ the bid function, and $F(v)$ the distribution of the bidder's value.

Optimal bidding function in Santa Claus auction with $n$ bidders is

$$
\begin{gathered}
\pi=F^{n-1}(b) \cdot(v-b)+\int_{v *}^{b} F^{n-1}(v) d v, \\
\pi=b^{n-1} v-b^{n}+\frac{b^{n}}{n}-\frac{\left(v^{*}\right)^{n}}{n}, \\
\frac{\partial \pi}{\partial b}=(n-1) \cdot b^{n-2} \cdot v-n \cdot b^{n-1}+b^{n-1}=0, \\
b^{n-2}(v-b)=0, \\
b=v .
\end{gathered}
$$

Santa Claus' gift to every bidder in a Santa Claus auction is

$$
S(b)=\int_{v *}^{b} F^{n-1}(v) d v=\frac{b^{n}}{n}-\frac{\left(v^{*}\right)^{n}}{n}=\frac{b^{n}-\left(v^{*}\right)^{n}}{n} .
$$

Optimal bid function in all-pay auction with $n$ bidders is

$$
\begin{gathered}
b(v)=v F^{n-1}(v)-\int_{v *}^{v} F^{n-1}(x) d x, \\
b(v)=v \cdot v^{n-1}-\int_{v *}^{v} x^{n-1} d x, \\
b(v)=v^{n}-\frac{v^{n}}{n}+\frac{\left(v^{*}\right)^{n}}{n} .
\end{gathered}
$$




\section{Variability of revenue in auctions}

Optimal bidding function in sad losers auction with $n$ bidders is as follows.

(i) Any bidder's expected revenue is $\pi=F^{n-1}(x) \cdot v-\left(1-F^{n-1}(x)\right) \cdot b(x)-c$.

(ii) Let $H(x)=\left(1-F^{n-1}(x)\right) \cdot b(x)$.

(iii) Revenue is maximized when $\partial \pi / \partial x=v \cdot(\partial / \partial x) F^{n-1}(x)-H^{\prime}(x)=0$.

(iv) $H^{\prime}(x)=v \cdot(\partial / \partial x) F^{n-1}(x)$.

At equilibrium, a bidder bids its valuation, that is, $x=v$,

$$
\begin{aligned}
H^{\prime}(v) & =v \cdot \frac{\partial}{\partial v} F^{n-1}(v), \\
H(v) & =\int_{v *}^{v} x \cdot d\left(F^{n-1}(x)\right)+k(\text { A. } 1) .
\end{aligned}
$$

Applying the expression of the expected revenue to $v^{*}$, then $\pi_{v *}=v^{*} \cdot F^{n-1}\left(v^{*}\right)-H\left(v^{*}\right)-$ $c^{*}=0$, and so $H\left(v^{*}\right)=v^{*} \cdot F^{n-1}\left(v^{*}\right)-c^{*}($ A.2). Equating (A.1) and (A.2),

$$
\begin{aligned}
k & =v^{*} \cdot F^{n-1}\left(v^{*}\right)-c^{*}, \\
H(v) & =\int_{v *}^{v} x \cdot d\left(F^{n-1}(x)\right)+v^{*} \cdot F^{n-1}\left(v^{*}\right)-c^{*} \\
& =v F^{n-1}(v)-\int_{v *}^{v} F^{n-1}(x) d x-c^{*} .
\end{aligned}
$$

If $F(x) \approx U[0,1]$, then

$$
H(v)=\frac{1}{n}\left((n-1) v^{n}+\left(v^{*}\right)^{n}-n c^{*}\right) .
$$

Using the original definition of $H(v)$,

$$
b(v)=\frac{H(v)}{1-v^{n-1}}=\frac{(n-1) v^{n}+\left(v^{*}\right)^{n}-n c^{*}}{n\left(1-v^{n-1}\right)} .
$$

Replacing $c^{*}=v^{*} F^{n-1}\left(v^{*}\right)=\left(v^{*}\right)^{n}$,

$$
b(v)=\frac{(n-1)\left(v^{n}-\left(v^{*}\right)^{n}\right)}{n\left(1-v^{n-1}\right)} .
$$

Optimal bid function in last-pays auction with $n$ bidders is

$$
\begin{gathered}
b(v)=\frac{v F^{n-1}(v)-\int_{v *}^{v} F^{n-1}(x) d x}{(1-F(v))^{n-1}}, \quad b(v)=\frac{v \cdot v^{n-1}-\int_{v *}^{v} x^{n-1} d x}{(1-v)^{n-1}}, \\
b(v)=\frac{\left(v^{*}\right)^{n}+(n-1) v^{n}}{n(1-v)^{n-1}} .
\end{gathered}
$$



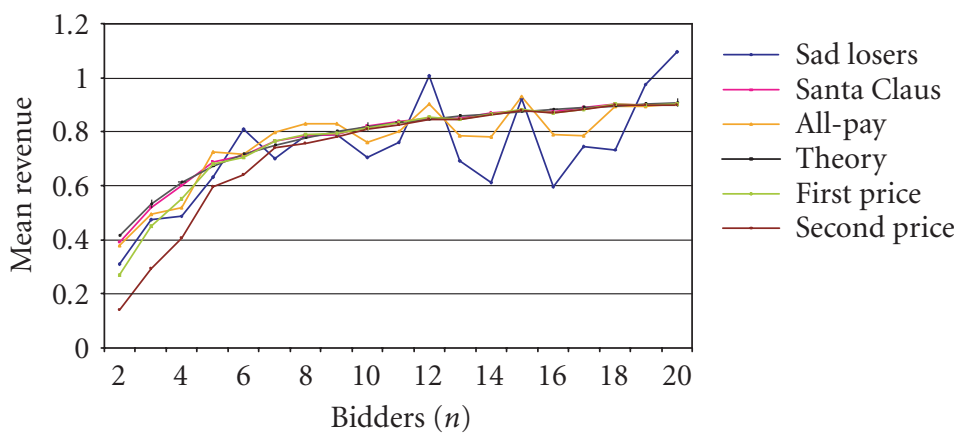

(a)

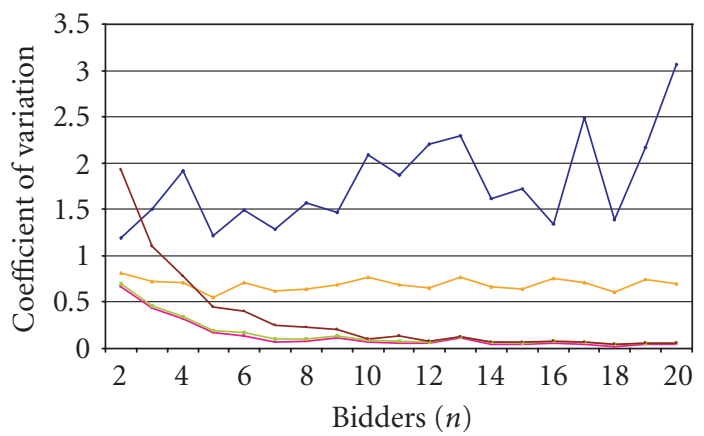

Sad losers

Santa Claus

All-pay

First price

Second price

(b)

Figure B.1. Results for 20 bidders and 100 scenarios.

Auctioneer's expected revenue is

$$
\begin{aligned}
& \pi=n \int_{v *}^{\bar{v}}\left(v F^{\prime}(v)+F(v)-1\right) \cdot F(v)^{n-1} d v, \\
& \pi=n \int_{v *}^{\bar{v}}(v+v-1) \cdot v^{n-1} d v, \\
& \pi=n\left[\frac{2 v^{n+1}}{n+1}-\frac{v^{n}}{n}\right]_{v *}^{\bar{v}}, \\
& \pi=\frac{2 n\left((\bar{v})^{n+1}-\left(v^{*}\right)^{n+1}\right)-(n+1)\left((\bar{v})^{n}-\left(v^{*}\right)^{n}\right)}{n+1} .
\end{aligned}
$$

\section{B. Simulation results}

Figures B.1 to B.11 show results for different numbers of bidders and scenarios. 


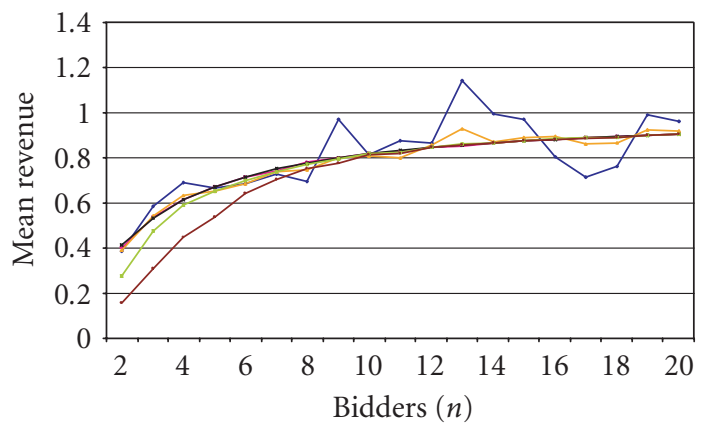

Sad losers

Santa Claus

All-pay

Theory

First price

Second price

(a)
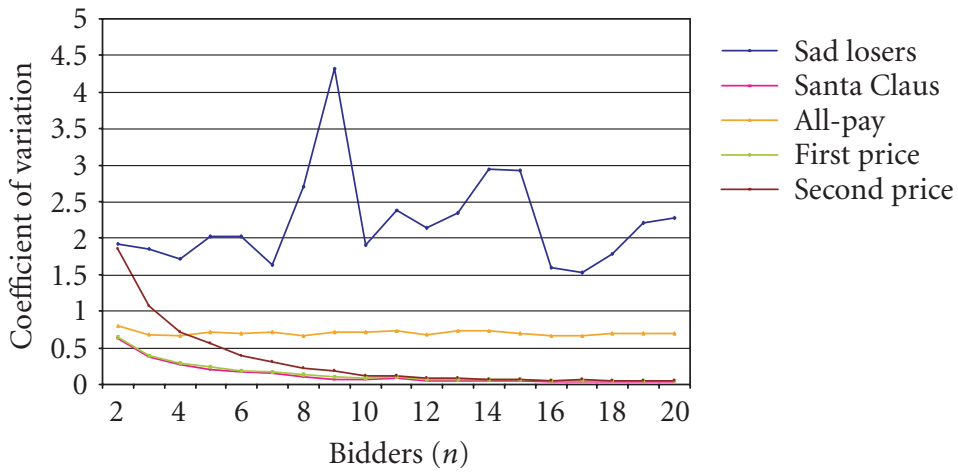

(b)

Figure B.2. Results for 20 bidders and 500 scenarios.
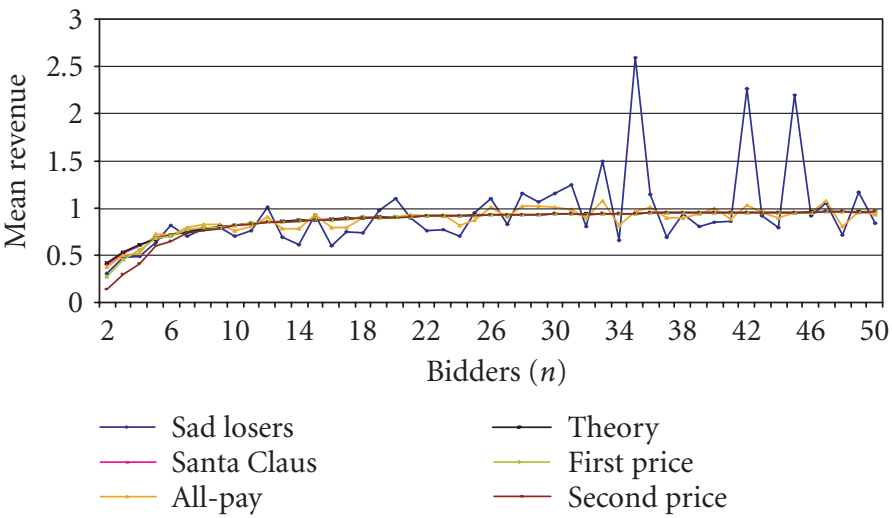

Figure B.3. Results for 50 bidders and 100 scenarios. 


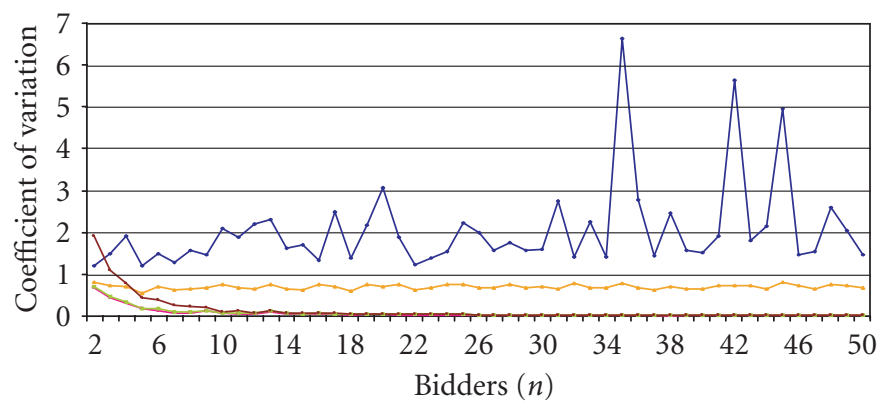

$\begin{array}{ll}\text { — Sad losers } & \text { First price } \\ \text { Santa Claus } & \text { Second price } \\ \text { All-pay } & \end{array}$

Figure B.4. Results for 50 bidders and 100 scenarios.

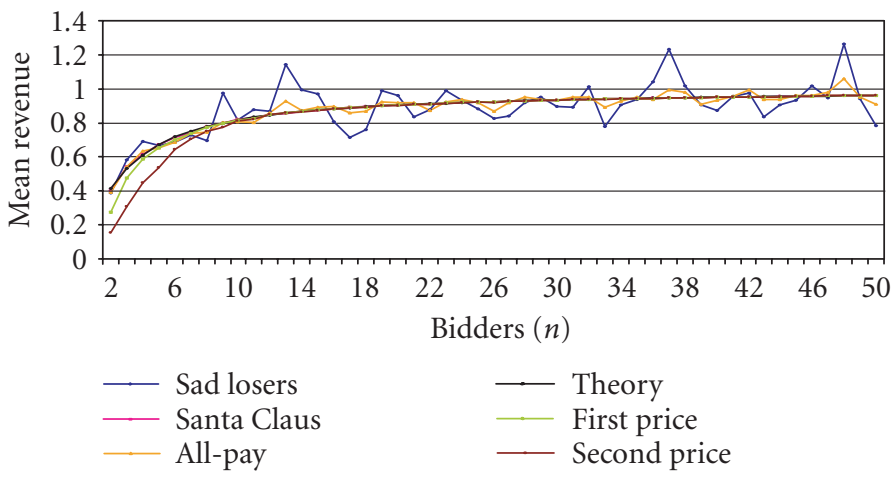

Figure B.5. Results for 50 bidders and 500 scenarios.

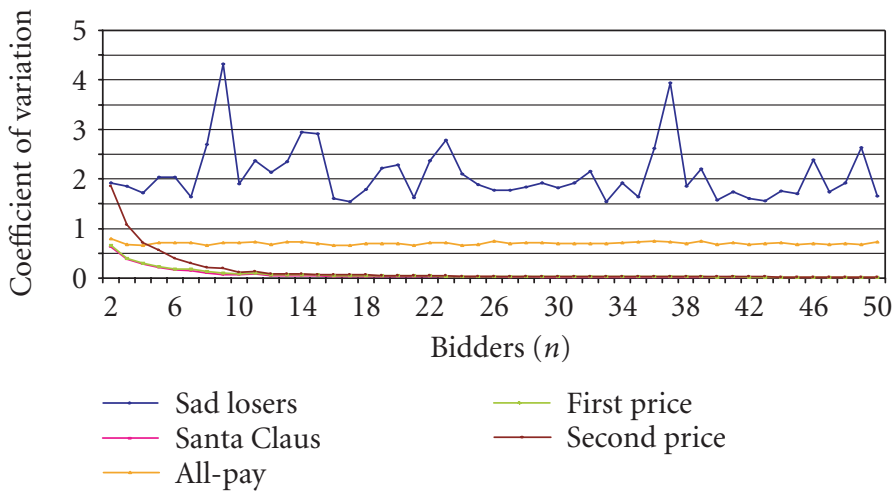

Figure B.6. Results for 50 bidders and 500 scenarios. 
12 Variability of revenue in auctions

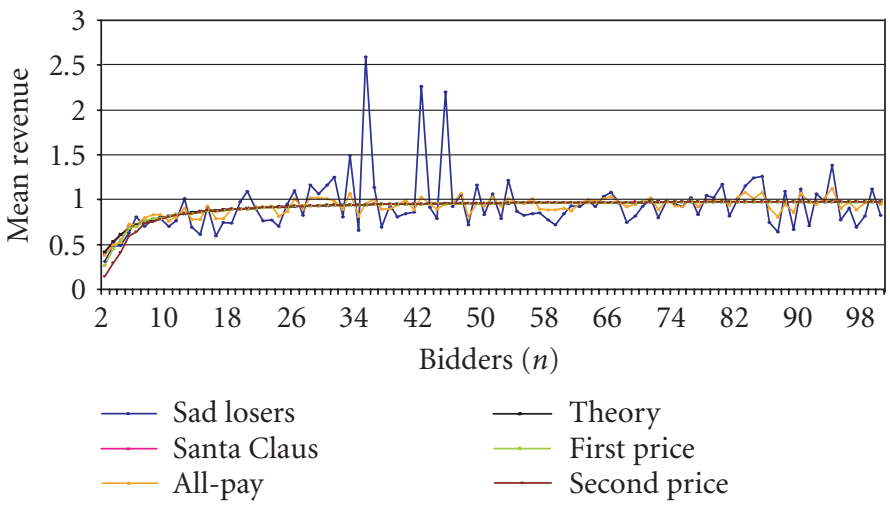

Figure B.7. Results for 100 bidders and 100 scenarios.

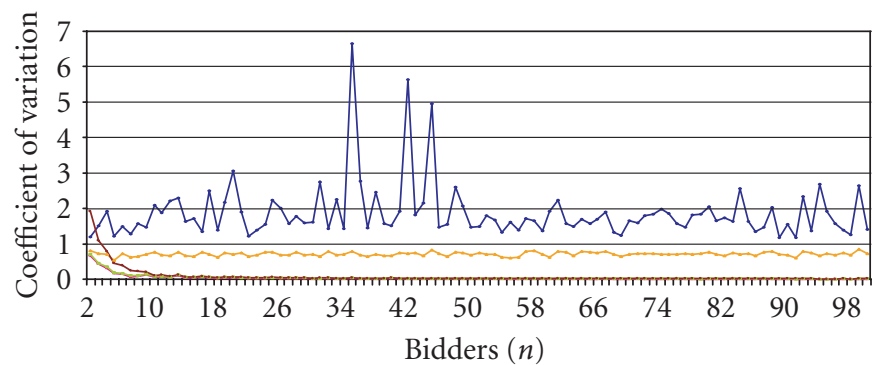

Sad losers

Santa Claus

First price

All-pay

Second price

Figure B.8. Results for 100 bidders and 100 scenarios.

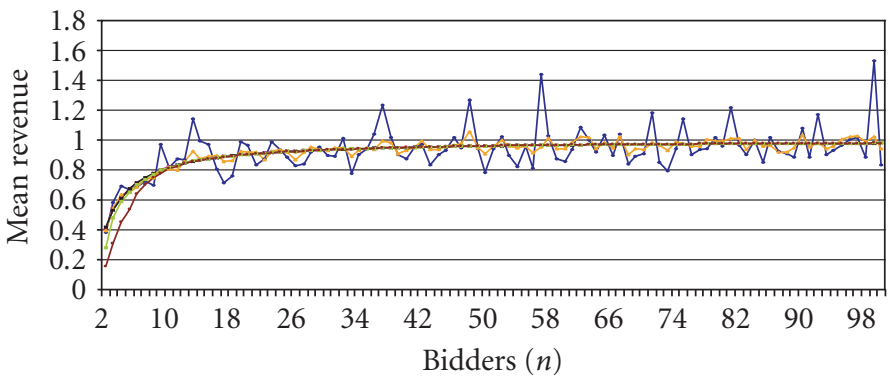
Sad losers
Santa Claus
All-pay
— Theory
First price
Second price

Figure B.9. Results for 100 bidders and 500 scenarios. 


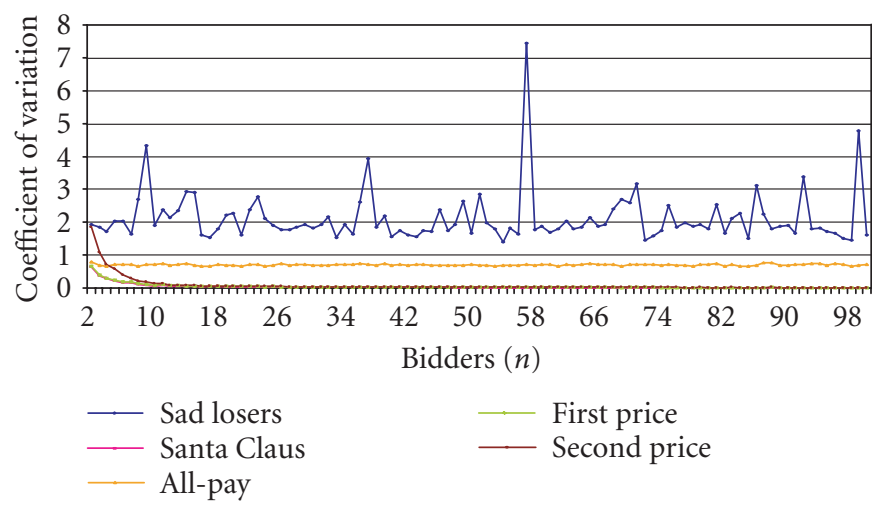

Figure B.10. Results for 100 bidders and 500 scenarios.

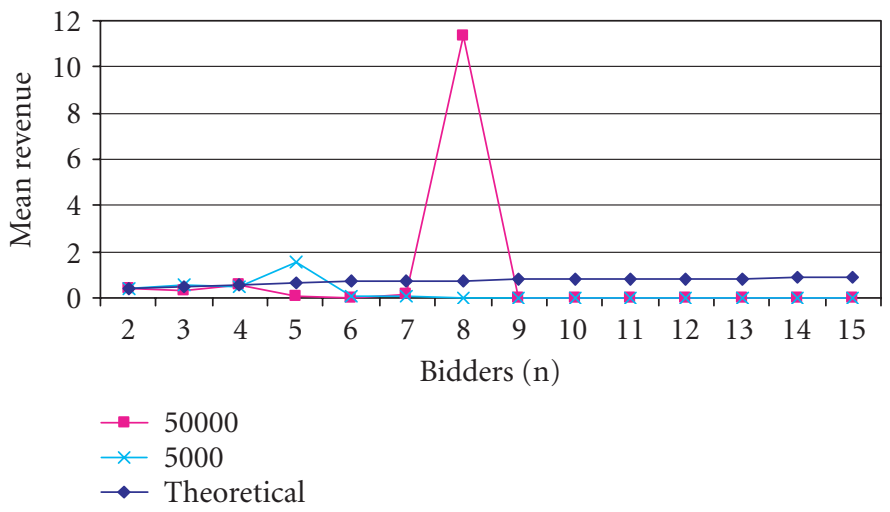

Figure B.11. Last-pay: 15 bidders, results from 5000 and 50000 scenarios.

\section{Acknowledgments}

A first version of this paper was presented at the 39th Annual Meeting, Operations Research Society of New Zealand, Auckland, November 2004. The authors want to especially thank the participation of Pamela Cardozo and Camilo Restrepo in a previous work that led to the ideas presented here. Camilo Restrepo provided an interesting explanation, based on his experimentation, of the strange behavior of the last-pays auction.

\section{References}

[1] F. Beltrán, N. Santamaría, C. Restrepo, and P. Cardozo, El teorema de ingreso equivalente para subastas de un objeto: Aproximación experimental, Revista de Ingeniería, Universidad de Los Andes. Marzo 17 (2003), 12-18.

[2] R. Gibbons, Game Theory for Applied Economists, Princeton University Press, New Jersey, 1992.

[3] P. Klemperer, Auctions: Theory and Practice, Princeton University Press, New Jersey, 2004. 


\section{Variability of revenue in auctions}

[4] P. Milgrom, Putting Auction Theory to Work, Cambridge University Press, Cambridge, 2004.

[5] R. B. Myerson, Optimal auction design, Mathematics of Operations Research 6 (1981), no. 1, $58-73$.

[6] J. G. Riley and W. F. Samuelson, Optimal auctions, American Economic Review 71 (1981), 381392.

[7] K. Waehrer, R. M. Harstad, and M. H. Rothkopf, Auction form preferences of risk-averse bid takers, RAND Journal of Economics 29 (1998), no. 1, 179-192.

Fernando Beltrán: Information Systems and Operations Management Department,

University of Auckland Business School, Auckland 1142, New Zealand

E-mail address: f.beltran@auckland.ac.nz

Natalia Santamaría: Departamento de Ingeniería Industrial, Universidad de los Andes, P.O. Box 4976, Bogotá, Colombia

E-mail address: n-santam@uniandes.edu.co

Current address: Rutgers Center for Operations Research (RUTCOR), Rutgers University, Piscataway, NJ 08854-8003, USA

E-mail address: ntobar@rutcor.rutgers.edu 


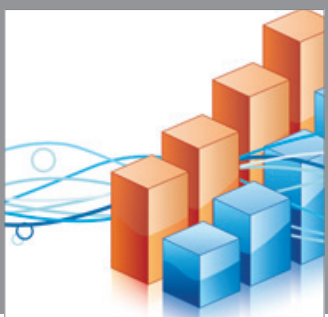

Advances in

Operations Research

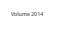

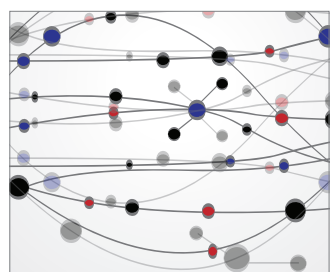

\section{The Scientific} World Journal
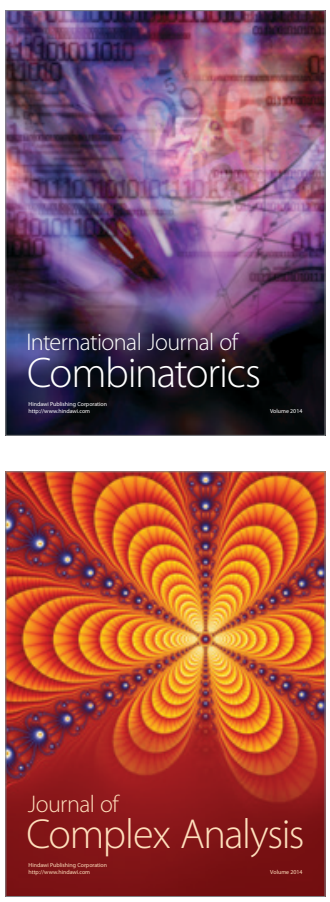

International Journal of

Mathematics and

Mathematical

Sciences
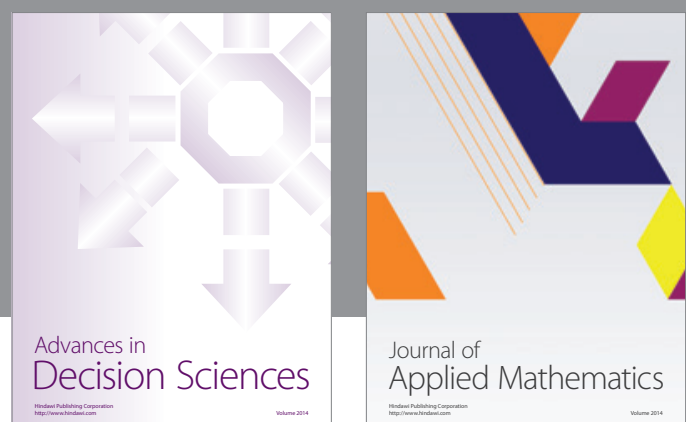

Journal of

Applied Mathematics
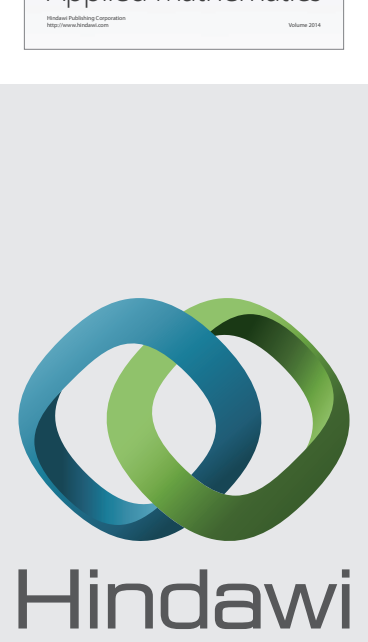

Submit your manuscripts at http://www.hindawi.com
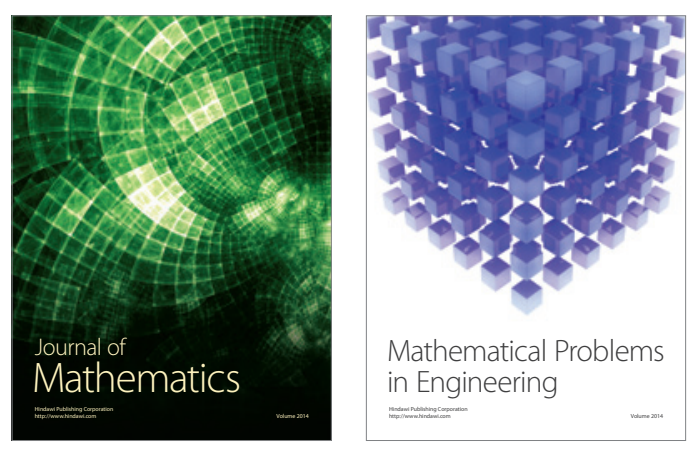

Mathematical Problems in Engineering
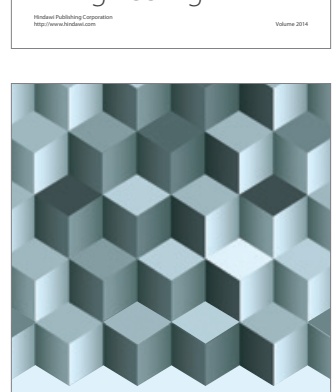

Journal of

Function Spaces
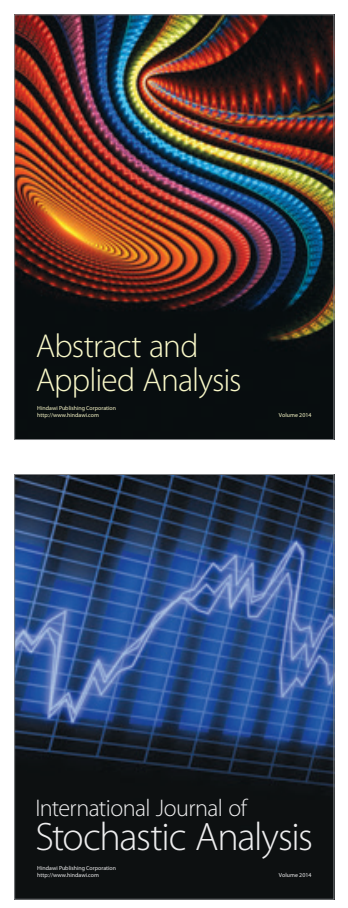

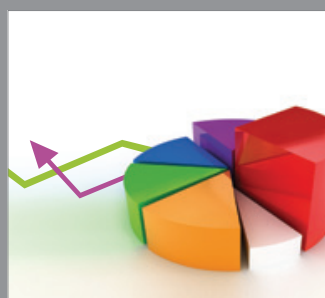

ournal of

Probability and Statistics

Promensencen
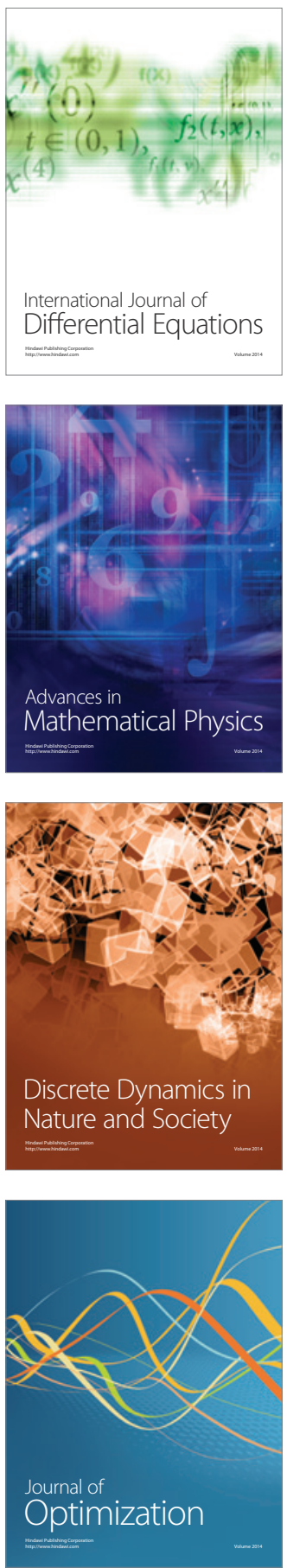